MECHANICAL RELIABILITY AND DESIGN 


\section{Other titles of related interest}

Design and Manufacture - An Integrated Approach

Rod Black

Form, Structure and Mechanism

M.J. French

Mechanical Reliability, Second Edition

A.D.S. Carter

Reliability for Engineers - An Introduction

Michael Beasley 


\title{
MECHANICAL RELIABILITY AND DESIGN
}

\author{
A.D.S. Carter \\ BSc, CEng, FIMechE, FRAeS \\ Professor Emeritus, \\ Royal Military College of Science \\ Hon Fellow, University of Wales, Swansea
}


(C) A.D.S. Carter 1997

Softcover reprint of the hardcover 1st edition 1997

All rights reserved. No reproduction, copy or transmission of this publication may be made without written permission.

No paragraph of this publication may be reproduced, copied or transmitted save with written permission or in accordance with the provisions of the Copyright, Designs and Patents Act 1988, or under the terms of any licence permitting limited copying issued by the Copyright Licensing Agency, 90 Tottenham Court Road, London W1P 9HE.

Any person who does any unauthorised act in relation to this publication may be liable to criminal prosecution and civil claims for damages.

The author has asserted his rights to be identified as the author of this work in accordance with the Copyright, Designs and Patents Act 1988.

First published 1997 by

MACMILLAN PRESS LTD

Houndmills, Basingstoke, Hampshire RG21 6XS

and London

Companies and representatives

throughout the world

ISBN 978-1-349-14489-1 ISBN 978-1-349-14487-7 (eBook)

DOI 10.1007/978-1-349-14487-7

A catalogue record for this book is available from the British Library.

This book is printed on paper suitable for recycling and made from fully managed and sustained forest sources.

$\begin{array}{rrrrrrrrrr}10 & 9 & 8 & 7 & 6 & 5 & 4 & 3 & 2 & 1 \\ 06 & 05 & 04 & 03 & 02 & 01 & 00 & 99 & 98 & 97\end{array}$

$\begin{array}{llllllllll}06 & 05 & 04 & 03 & 02 & 01 & 00 & 99 & 98 & 97\end{array}$ 


\section{Contents}

Preface

vii

Notation

ix

Glossary

xiii

1 Introduction $\quad 1$

$\begin{array}{ll}\text { References } & 10\end{array}$

2 Conventional design $\quad 11$

2.1 Stress-rupture failure modes 11

$\begin{array}{ll}2.2 \text { Wear-out failure modes } & 16\end{array}$

$\begin{array}{ll}2.3 \text { Achieving reliability by conventional design } & 19\end{array}$

$\begin{array}{ll}\text { References } & 20\end{array}$

3 Review of basic statistics $\quad 21$

$\begin{array}{lll}3.1 & \text { Statistical distributions } & 21\end{array}$

3.2 Strength distributions $\quad 30$

3.3 Load distributions 41

3.4 The use of statistical distributions in reliability theory 44

3.5 Statistical interpretation of reliability terminology 45

3.5.1 Non-repairable parts and components 48

3.5.2 Repairable components and systems $\quad 50$

References $\quad 52$

4 Statistical design: stress-rupture modes $\quad \mathbf{5 4}$

4.1 Basic statistical design methodology $\quad 54$

$\begin{array}{ll}4.2 \text { Statistical and worst-case design } & 62\end{array}$

$\begin{array}{ll}\text { References } & 69\end{array}$

5 The factor of safety: stress-rupture modes $\quad \mathbf{7 0}$

5.1 Statistical evaluation of the factor of safety 70

$\begin{array}{ll}5.2 \text { Comparison of theory and experience } & 73\end{array}$

5.2.1 Calculation of factors of safety 73

5.2.2 Appraisal of factors from 5.2.1 75 
5.3 The factor of safety in perspective $\quad 77$

$\begin{array}{lll}5.3 .1 & \text { Expertise } & 78\end{array}$

$\begin{array}{lll}\text { 5.3.2 } & \text { Statistical distributions } & 78\end{array}$

$\begin{array}{lll}5.3 .3 \text { Audit } & 79\end{array}$

$\begin{array}{lll}5.3 .4 & \text { Stresses } & 79\end{array}$

$\begin{array}{ll}\text { 5.3.5 Conclusions } & 80\end{array}$

$\begin{array}{ll}\text { References } & 80\end{array}$

6 Wear and wear-out $\quad 81$

$\begin{array}{lll}6.1 & \text { Introduction } & 81\end{array}$

6.2 The $s-N$ distribution $\quad 86$

$\begin{array}{llr}6.2 .1 & \text { Fatigue } & 89\end{array}$

$\begin{array}{ll}\text { 6.2.2 Other failure mechanisms } & 111\end{array}$

6.3 The wear-out life distribution $\quad 116$

$\begin{array}{ll}\text { References } & 121\end{array}$

Appendix: The Weibull representation of data below the knee 122

7 Statistical design: wear modes $\quad 124$

$\begin{array}{ll}7.1 \text { A simple design method } & 124\end{array}$

$\begin{array}{lll}7.1 .1 & \text { Distributions } & 127\end{array}$

$\begin{array}{lll}7.1 .2 & \text { Sensitivity } & 137\end{array}$

$\begin{array}{lll}7.1 .3 & \text { Miner's rule } & 141\end{array}$

$\begin{array}{lll}\text { 7.1.4 Review of difficulties } & 144\end{array}$

7.2 Comparison of statistical and empirical design 145

$\begin{array}{ll}\text { References } & 149\end{array}$

8 A design methodology 151

9 Miscellaneous supporting techniques $\quad 158$

$\begin{array}{lll}9.1 \text { Checklists } & 158\end{array}$

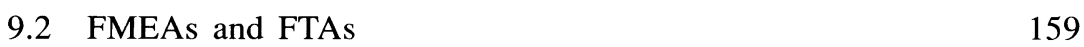

$\begin{array}{ll}\text { 9.3 Design reviews and design audits } & 161\end{array}$

References 163

10 Design strategy $\quad 164$

10.1 The overall design activity 164

$\begin{array}{ll}10.2 \text { Design for economic reliability } & 171\end{array}$

$\begin{array}{lr}10.3 \text { Reliability apportionment } & 180\end{array}$

$\begin{array}{ll}10.4 \text { The strategy } & 183\end{array}$

$\begin{array}{ll}\text { References } & 184\end{array}$

Appendix 1: Water pump reliability specification 184

Appendix 2: The reliability of a series system 185

11 A final review 190

$\begin{array}{ll}\text { Index } & 197\end{array}$ 


\section{Preface}

Following the publication of my earlier book in 1986 I lectured to a number of specialist courses, seminars and the like on various parts of its contents. Gradually, these lectures concentrated more and more on the design aspects of mechanical reliability, which many saw as the key area. Having retired from this activity, I have brought together the final form of these various lectures in a more developed format in this book. The background has been filled in more fully than was possible in the limited time for lectures, and continuity material has been added. The opportunity has been taken to dot a lot of i's and cross many t's of the supporting theory so as to produce a coherent picture of the role of reliability, particularly as a quantitative requirement, in the design of mechanical machines and components and, in particular, their constituent parts.

Like the lectures on which it is based, the book is aimed at practising mechanical engineers; but, like the lectures, it could be used in specialist courses and seminars. Additionally, parts of it could well be included in courses on mechanical design at first degree level. I do not see how the education of any mechanical engineer can be considered complete without some reference to quantified statistical reliability, and to the impact of specifications for such reliability on design.

The book makes full use of statistical reliability concepts, but crucial fundamental aspects are critically reviewed before use. In the event it was found that surprisingly little statistics is actually needed for a design methodology aimed to meet a quantified reliability, but it was found necessary to delve a little further into materials science than is customary. I hope that the reader, having read the book, will accept that a design methodology based on statistically defined input data to meet a quantified reliability specification is feasible, not too different from contemporary practice, and not difficult to implement. I hope too that he or she will be prepared eventually to say goodbye to all the uncertain empiricism that surrounds so much of contemporary design.

Finally, I wish to acknowledge my indebtedness to all those reliability workers who have carried out and reported stochastic test data on materials and components, both those quoted in this book and those consulted but not quoted. 
viii

PREFACE

Full reference has been given in the text to all quoted data, so that the reader may consult the original work. Obtaining worthwhile data is very time consuming and laborious, but those data are the bedrock of all our knowledge. My thanks to them all, especially to British Coal for permission to use previously unpublished data in the case study of Chapter 7.

A.D.S. Carter

Oxford 1996 


\section{Notation}

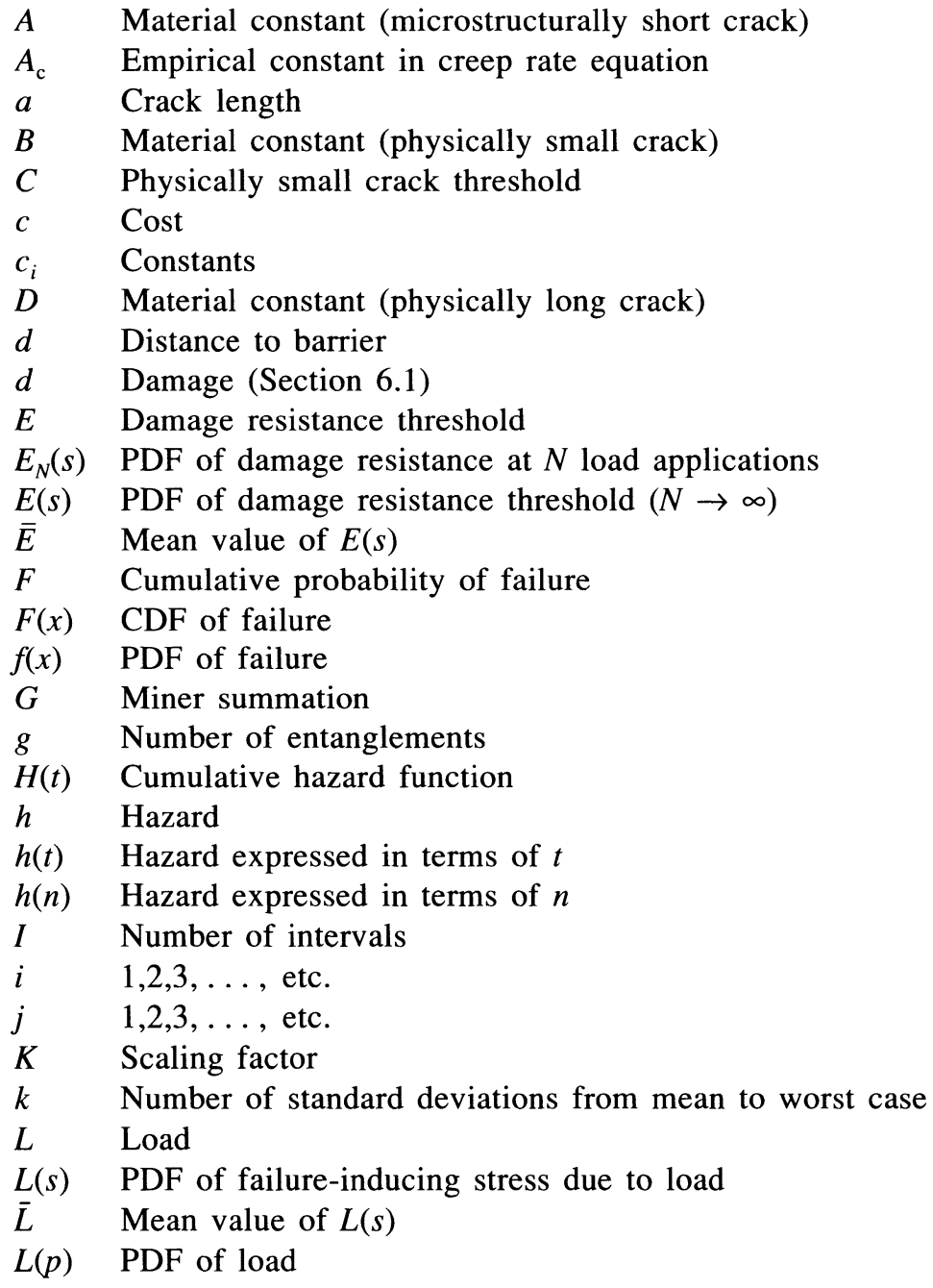


$\bar{L}(p) \quad$ Mean value of $L(p)$

$L R \quad$ Loading roughness

$l \quad$ Number of loads

$M \quad$ Maintainability

$M P \quad$ Mean probability (mean rank)

$M z \quad$ A Weibull function

$m \quad$ Index in power relationship

$N \quad$ Number of load applications to failure

$n \quad$ Number of load applications

$P \quad$ Probability

$p \quad$ Force or other impressed phenomenon

$Q \quad$ Total number of items in population

$Q_{\text {c }} \quad$ Activation energy for creep

$q \quad$ Number of items

$R \quad$ Reliability (cumulative probability of no failure)

$R \quad$ Universal gas constant (section 6.2.2)

$R(n) \quad$ Reliability expressed in terms of $n$

$R(t) \quad$ Reliability expressed in terms of $t$

$R(c) \quad$ Rockwell $-c$ scale

$S \quad$ Strength

$S(s) \quad$ PDF of strength at critical section

$\bar{S} \quad$ Mean value of $S(s)$

$S M \quad$ Safety margin

$s \quad$ Stress

$T \quad$ Time to failure

$t \quad$ Time

$\Sigma t \quad$ Cumulative operating time

$t^{\prime} \quad$ Time from different origin

$t_{\mathrm{o}} \quad$ Weibull locating constant

$U \quad$ Ultimate tensile strength

$\bar{U} \quad$ Mean ultimate tensile strength

$u \quad$ Cross-sectional area

$V(s) \quad$ PDF of strength modification during manufacture

$\bar{V} \quad$ Mean of $V(s)$

$W \quad$ Number of breakdowns

$\Sigma W \quad$ Cumulative breakdowns

$X \quad$ General arbitrary material property

$x \quad$ General arbitrary variable/variate

$Y \quad$ Yield strength

$Z \quad$ Attribute

$z \quad s_{F}-s_{50}$

$\alpha \quad$ Material constant (microstructurally short crack)

$\beta \quad$ Material constant (physically small crack)

$\beta \quad$ Weibull shaping parameter 
$\gamma \quad$ Coefficient of variation

$\varepsilon \quad$ Strain

$\Delta \gamma_{\mathrm{p}} \quad$ Shear plastic strain range

$\Delta K \quad$ Stress intensity factor

$\zeta \quad s-N$ function

$\eta \quad$ Characteristic life

$\theta \quad$ Number of tests

$\lambda \quad$ Breakdown rate

$\mu \quad$ Mean value

$v \quad$ Duane index

$\sigma \quad$ Standard deviation

$\tau \quad$ Temperature

$\phi \quad$ Factor of safety

$\omega \quad$ Maintenance cost index

\section{Subscripts}

a Average

c Refers to strength collapse

c Value at confidence limit

d Defects

E Refers to damage resistance threshold

$F \quad$ Value for $F \%$ failures

g Refers to entanglements

$i \quad$ Successive values $1,2,3, \ldots$, etc.

$j \quad$ Successive values $1,2,3, \ldots$, etc.

$1 \quad$ Lower limit

$L \quad$ Refers to load

m Of mean

max Maximum perceived value

min Minimum perceived value

$N \quad$ Value at $N$ load applications

nom Nominal value

O Reference or arbitrary value

o Original or initial value

op Operational

$\mathrm{p} \quad$ Value for process

S Refers to strength

$\mathrm{SH} \quad$ Refers to strain hardening

$\mathrm{U} \quad$ Refers to ultimate tensile strength

u Upper limit

$\mathrm{Y} \quad$ Refers to yield strength

0 Lowest acceptable value

* Minimum physically small crack 
xii NOTATION

Index

* Specified value

Note: SI units are used throughout, except that original data have been quoted as such, i.e. in the originator's units. The SI equivalent is always given when the quantity could have general significance. 


\section{Glossary}

assembly See hierarchy of mechanical artefacts.

break down To rupture the continuity of performing a given function. To disrupt or stop for a time.

breakdown rate The rate at which breakdowns occur.

component See hierarchy of mechanical artefacts.

damage A change in a material structure.

damage resistance The ability of a material to resist damage by a load or other hostile environment.

fail To become exhausted; to come to an end.

failure The termination of the ability to perform a required function. The inanimate equivalent of death.

failure rate Term not used in this book.

field 'In the field' or 'in service' implies that the product is in the hands of the intended user, and data so described refer solely to his/her/their use of the product. Tests or trials of any kind are specifically excluded.

hazard The non-dimensionalised rate at which failures occur in a nonmaintained component or part. For the mathematical definition see section 3.5 (equation 3.36).

load Any hostile environment that can give rise to a failure. See Chapter 1 for a comprehensive definition.

hierarchy of mechanical artefacts There is no standardised terminology, but the following definitions apply to their usage in this book. (Given in hierarchical order, not alphabetical.)

system A combination of integral machines and components to achieve a specified output(s). 
subsystem A convenient subset of a system made on various different criteria, such as providing one of several different inputs to the system, operating on an identifiable basis (e.g. hydraulic), contained as an integral package, provided by a given supplier, and so on, Can be extended to sub-subsystem, etc.

machine An integral assembly of components and parts to achieve a defined output or related series of outputs. The lowest subsystem level, but could well be a stand-alone artefact.

assembly A package of components and parts that comprises the machine. The package is usually determined by manufacturing or handling convenience rather than any functional attribute, though they may well coincide. Can be extended to sub-assembly, etc.

component An identifiable self-contained unit, to perform a given function, made up of several or many parts. The lowest assembly level. It may or may not be maintainable.

part The fundamental mechanical artefact, which cannot be dismantled. Essentially, it is completely defined by a detail working drawing - to use old nomenclature - or by a modern electronic record or hard copy. Hence often referred to as a 'detail' in the literature. The word 'piece' is also often used, especially for a part made specifically for test (testpiece). A part or piece is not maintainable except by replacement.

product Can be any of the above, but generally excluding systems. The final output of a manufacturer or manufacturing organisation.

item A single constituent of a statistical population on which an observation or measurement is made. Sometimes called 'specimen' in statistical literature.

\section{machine See hierarchy of mechanical artefacts.}

operational reliability The ability of a system/product to perform the required function under stated conditions of use and maintenance for a stated period of time.

\section{part See hierarchy of mechanical artefacts.}

population The totality of items possessing specified attributes. The whole product.

prototype The first or primary version of any product. It is used to establish the feasibility of the product and as a model for subsequent full production. There may be several prototypes.

product See hierarchy of mechanical artefacts. 
reliability The ability of a system/product to perform the required function under stated conditions of use for a stated period of time.

ROCOF Acronym for the rate of occurrence of failures; equivalent of breakdown rate.

sample A subset of a population.

service See field.

standard $s-N$ curve The $s-N$ curve derived by contemporary conventional practices. It is truly neither the mean nor the median curve, but is closer to the latter.

strength The ability to resist a compatible load without failure at any given instant. A product may have several different strength attributes.

stress-rupture A failure mechanism in which failure, rupture, or fracture of the material may take place on application of a load, but if not the material structure remains unchanged.

system See hierarchy of mechanical artefacts.

threshold The limit state above which damage may be inflicted and below which no damage can be done.

variation A difference in a property of the items making up a population. It includes both the statistical variance (or standard deviation) and the shape of the distribution.

wear A failure mechanism in which no failure, rupture, or fracture necessarily takes place on the application of a load, but there is a change in the material structure (i.e. damage is done). Failure takes place when the cumulative damage reaches some critical value.

wear-out The period of time during which wear failures take place. 